\title{
Cante lá que eu canto cá: a construção do livro- objeto e o registro do processo criativo com o uso de tecnologias digitais
}

Francisco Kelson Moreira de Sousa

resumo:

"Cante lá que eu canto cá" é um livro-objeto criado com técnicas de experimentação gráfica. Seu processo criativo foi registrado em fotos e vídeos e compartilhado em rede, em tempo real, com ajuda de um smartphone e acesso à internet. Com o arcabouço teórico da Crítica Genética, foi possível retomar a história de criação deste produto por meio das fotos, vídeos, rascunhos e demais documentos gerados ao longo do processo de criação. Essa retomada não só enriquece o discurso acerca da obra criada, como mostra um pouco do próprio autor, suas referências culturais e históricas.

\section{palavras-chave:}

Livro-objeto; Crítica Genética; Processo Criativo 


\section{Introdução}

"Cante lá que eu canto cá" é o título de um livro-objeto ${ }^{1}$ desenvolvido para uma disciplina de livros experimentais, durante um curso de Pós-Graduação em Design Editorial. O título revela também seu conteúdo: trata-se de uma poesia clássica da literatura de cordel, de autoria de Patativa do Assaré ${ }^{2}$.

Seu processo de criação foi todo registrado em fotos, vídeos, rascunhos e anotações. E o material gerado foi disponibilizado em pasta compartilhada na internet, gerando uma documentação importante para posterior análise do produto final.

O objetivo desse artigo é relatar nossa experiência com a criação do livro-objeto citado acima, lançando mão da teoria da Crítica Genética para observação mais atenta aos documentos de registro do processo criativo, entendendo o produto final como uma fase necessária desse processo e não simplesmente como uma obra acabada.

\section{Fundamentação teórica}

Para fundamentação teórica sobre a Crítica Genética utilizamos principalmente três publicações de Cecília Almeida Salles. A primeira, Gesto inacabado: processo de criação artística, de 1998, aborda o que ela chama de estética do movimento criador, onde explica o papel do pesquisador ao narrar as etapas de criação, emoldurando o processo e revelando a metamorfose da obra em suas diversas fases de materialização. Para a autora esse processo é como um labirinto, onde os documentos de criação são como rastros que, ao serem seguidos, nos permitirão conhecer de forma mais profunda a obra e o artista.

A segunda publicação de Cecília que utilizamos é Redes da Criação: construção da obra de arte, de 2006. Nela a autora retoma de forma complementar os conceitos abordados no Gesto inacabado, mas agrega à discussão o conceito de uma construção em rede e trata do papel das mídias digitais e de pesquisadores que passaram a conviver com o percurso criativo em tempo real, gerando, assim, a necessidade de "novas metodologias para abordar seus processos de criação [...] que dessem conta de múltiplas conexões em permanente mobilidade" (SALLES, 2006). A partir disso a autora passa a pensar na criação como rede de conexões, que se torna mais complexa à medida em que novas relações vão sendo estabelecidas.

A terceira publicação da mesma autora é Crítica genética: fundamentos dos estudos genéticos sobre o processo de criação artística, de 2008. Na verdade trata-se da terceira edição da obra. Listamos aqui por último simplesmente para seguir a ordem cronológica de publicação, mas, como o próprio título expõe, trata-se dos fundamentos básicos da Crítica Genética, atualizados desde a primeira edição, lançada em 1992. É, portanto, um livro de introdução ao assunto.

Igualmente importante para a compreensão sobre o assunto são os textos de Philippe Wilemart, Louis Hay e Almuth Grésillon que podemos encontrar tanto no livro Criação em processo: ensaios de crítica genética, quanto na Manuscrítica: Revista de Crítica Genética.

O primeiro é um livro organizado por Roberto Zular em 2002 onde encontramos um texto importantíssimo de Almuth Grésillon que trata da diferenciação entre Filologia e Crítica Genética ressaltando justamente o interesse desta última pelo processo em detrimento da obra final.

Nessa mesma linha vamos encontrar aí um artigo de Louis Hay defendendo a ideia de que o texto (entendido aqui como a obra finalizada) não pode ser o objetivo final dos estudos literários, mas que

\footnotetext{
${ }^{1} \mathrm{O}$ livro-objeto se distingue de um livro convencional por proporcionar uma transformação na estrutura narrativa através do suporte em que se apresenta, da sua materialidade e da sua linguagem com narrativa ao mesmo tempo poética e funcional. "O livro-objeto não se conforma em ser apenas um objeto que suporta a tinta das palavras ou as imagens impressas, ele se situa entre um brinquedo e um livro, já que propicia a interação não apenas por meio da leitura visual convencional, pois essa se dá também manualmente" (GUZMAN, 2015)

${ }^{2}$ Patativa do Assaré, foi um poeta popular, cordelista, improvisador e compositor de grande significação para a cultura popular brasileira. Cearense de pouco estudo, mas grande sabedoria, viveu entre 1909 e 2002, na cidade de Assaré. Tem vários livros publicados em seu nome, incluindo “Cante lá que eu canto cá”, publicado em 1978.
} 
deve ser visto tão somente como um mal necessário diante da urgência de apresentação pública do trabalho.

Já a Manuscrítica é uma revista semestral da Associação dos Pesquisadores em Crítica Genética, disponível na internet e editada desde 1990, onde encontraremos um rico apanhado de artigos dos mais diversos autores sobre o assunto, incluindo nomes aqui já citados.

De igual importância traremos também para a reflexão o texto de René Passeron, Da estética à poiética, que ressalta, na conduta criadora, o papel do autor da obra, de cujo resultado estético é dependente.

Para tratar da história e conceitos sobre livro e livro-objeto utilizamos a obra de Martyn Lyons, Livro: uma história viva, que apresenta a evolução e a influência dos livros em todo o mundo desde o seu surgimento até os livros digitais. Igualmente importante é a publicação $O$ livro e o designer II: como criar e produzir livro, de Andrew Haslam, principalmente o capítulo 4, que trata da manufatura e traz os conceitos relativos à engenharia do papel. E finalmente, utilizamos a dissertação de mestrado de Cindy Guzman, intitulada Aprendendo através de imagens: o livro-objeto, que será importante não somente para a conceituação de livro-objeto, mas também sobre questões relativas ao aprendizado durante o processo criativo.

\section{Cante lá que eu canto cá}

A ideia de criar um livro inteiro com apenas uma poesia do poeta popular Patativa do Assaré, nasceu em sala de aula durante uma disciplina de livros experimentais. A professora sugeriu três ou quatro textos de autores diferentes e pediu que a turma criasse um livro experimentando técnicas manuais. $\mathrm{O}$ produto final deveria contar também com uma embalagem e durante sua apresentação cada aluno deveria mostrar, com imagens, o seu processo criativo.

Sobre o livro-objeto "Cante lá que eu canto cá", trata-se de um único exemplar, todo feito à mão. Em seu processo de criação, tomamos como referências visuais uma série de folhetos de $\operatorname{cordel}^{3}$, além de xilogravuras ${ }^{4}$ de diversos artistas catalogados na xiloteca virtual do Centro Nacional de Folclore e Cultura Popular ${ }^{5}$.

Para fazê-lo, utilizamos algumas técnicas de experimentação gráfica. As ilustrações do livro, por exemplo, foram feitas com carimbos que esculpimos manualmente em borrachas escolares (Imagem 1). As imagens foram então criadas com carimbadas e utilizando poucas cores (basicamente o preto, o vermelho e o azul, que são as tintas para carimbo disponíveis nas papelarias).

\footnotetext{
${ }^{3}$ Conforme Brasil (2005), os "folhetos de cordel são folhas de papel dobradas e encadernadas em tamanho de 11 x $16 \mathrm{~cm}$ ”. São impressos tradicionalmente em oficinas tipográficas e o formato que ficou tradicionalmente conhecido, tem a capa ilustrada por uma xilogravura. As narrativas do cordel tem uma métrica regular que ressalta uma musicalidade no texto. "Contam histórias, romances, acontecidos, duelos, pelejas, vidas, mortes, encontros no céu, casos de pessoas que se transformam em animais, de bichos que falam, de seres fantásticos, alimentam mitos e comentam sobre qualquer assunto". (BRASIL, 2005, p.23)

${ }^{4}$ As xilogravuras são feitas pela impressão (sobre papel, no caso dos folhetos de cordel) de uma matriz entalhada em madeira. Trata-se de um dos processo de impressão mais antigos de que se tem conhecimento. Os chineses já a utilizavam a mais de um milênio e meio, para impressão de orações budistas, cartas de baralho, papel moeda, etc.

${ }^{5}$ http://www.cnfcp.gov.br/interna.php?ID_Secao $=64$
} 


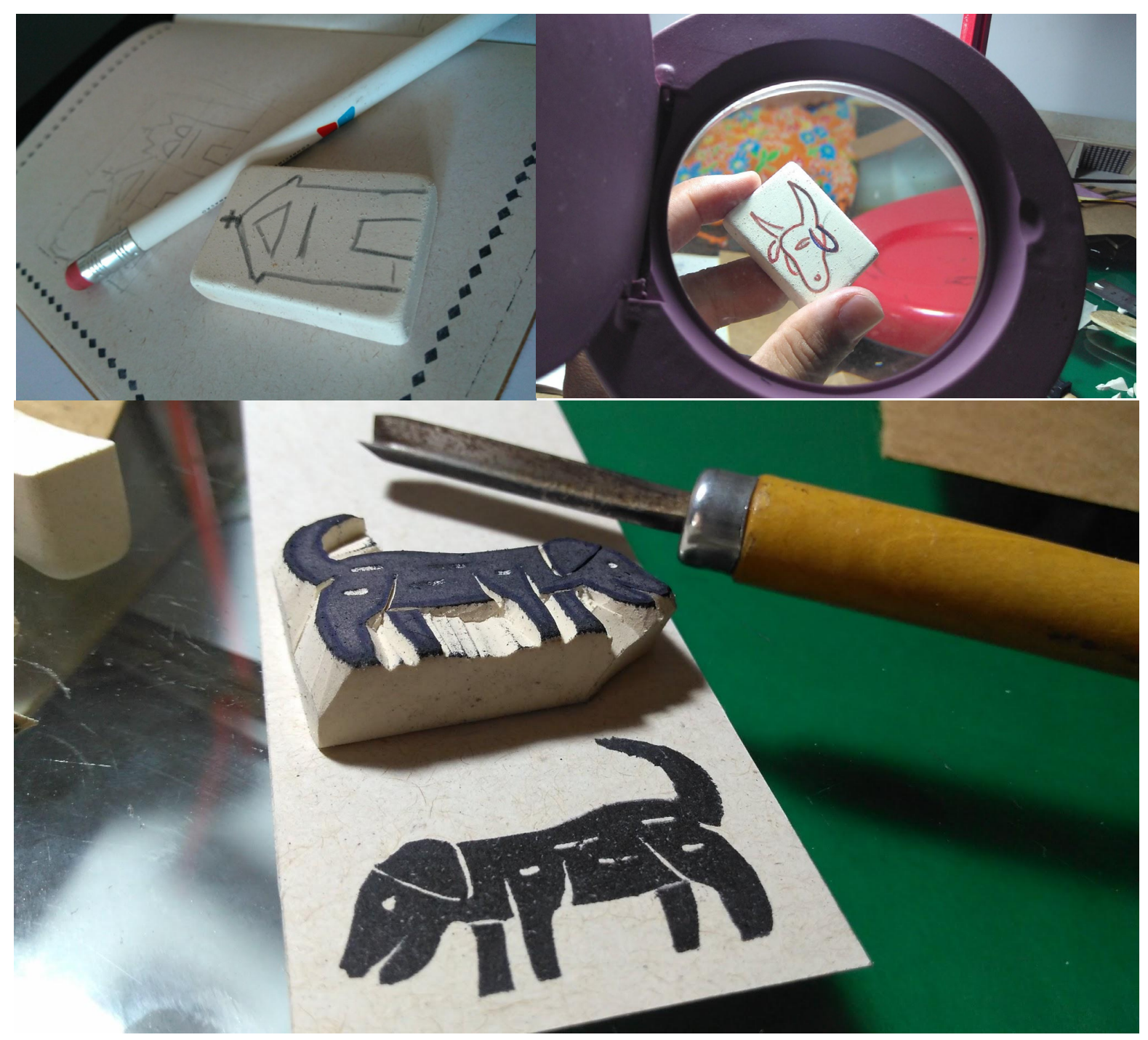

Imagem 1 - Para as ilustrações, criamos uma série de carimbos artesanais em borrachas escolares.

(Fonte: arquivo do autor. 2018)

Já a parte textual foi trabalhada com auxílio de programas de computação gráfica, mas optamos por desconstruir a estrutura de blocos de texto do cordel e trabalhar linhas com movimento, ressaltando a musicalidade tradicional desse gênero literário.

$\mathrm{Na}$ montagem do livro, optamos por experimentar algumas técnicas simples de engenharia do $\mathrm{papel}^{6}$, aumentando o nível de interatividade com o leitor (Imagem 2). As imagens, portanto, se movimentam. Elevam-se para além do plano da página.

Finalmente, ressaltamos a embalagem que criamos para o produto (Imagem 3). Feita de madeira, com tampa dividida horizontalmente em duas partes, fazendo referência às portas de algumas casas do sertão nordestino, que são igualmente divididas.

\footnotetext{
${ }^{6}$ A engenharia do papel consiste em manipulações feitas em papel - cortes, dobras, colagens - com o objetivo de criar estruturas que "aproveitam a energia cinética do movimento das folhas do livro para criar modelos tridimensionais que saltam das páginas" (HASLAM, 2007, p.200). Esses modelos são chamados de pop-ups e seu desenvolvimento é um processo que exige muita testagem, na maioria das vezes "na base da tentativa e erro, incluindo o corte e a dobragem de muitos protótipos para se obter o resultado desejado" (Ibid.).
} 


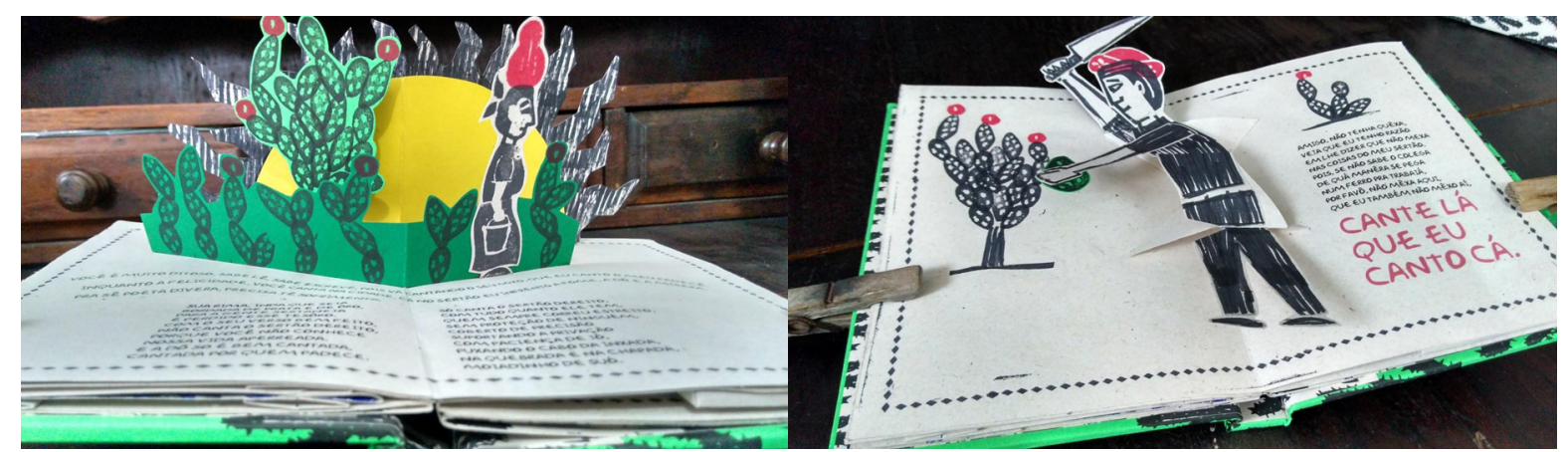

Imagem 2 - Páginas internas com exemplos de ilustrações que se projetam para fora do livro (Fonte: arquivo do autor. 2018)

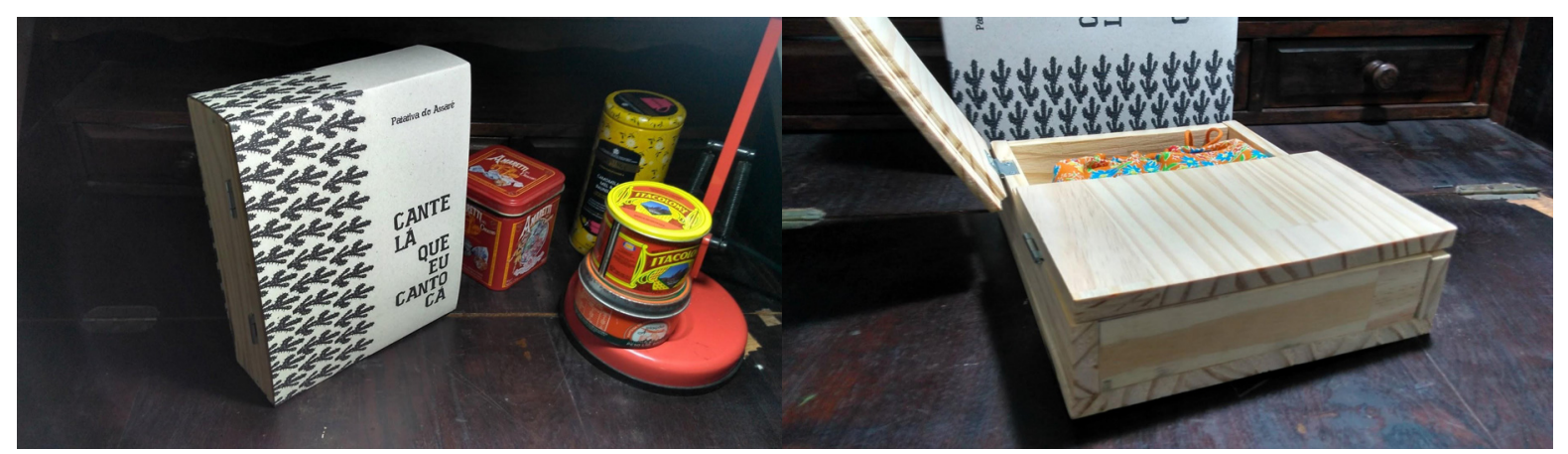

Imagem 3 - À esquerda, luva que envolve a embalagem do livro. À direita, caixa de madeira com tampa dividida em duas partes. (Fonte: arquivo do autor. 2018)

Na medida em que o processo criativo foi se desenvolvendo, fomos registrando todos os passos com fotos e vídeos feitos com o auxílio de um celular. Essas imagens iam sendo imediatamente compartilhadas na internet utilizando o Google Photos, aplicativo nativo dos smartphones Android. O arquivo digital podia ser visto em tempo real e posteriormente por qualquer pessoa com o link de acesso. E para facilitar, criamos um QRCODE que imprimimos no verso da embalagem (Imagem 4) e também em um encarte que acompanha o livro. Desse modo, basta apontar a câmera do celular na direção do código que o usuário é direcionado ao álbum de fotos (Imagem 5).

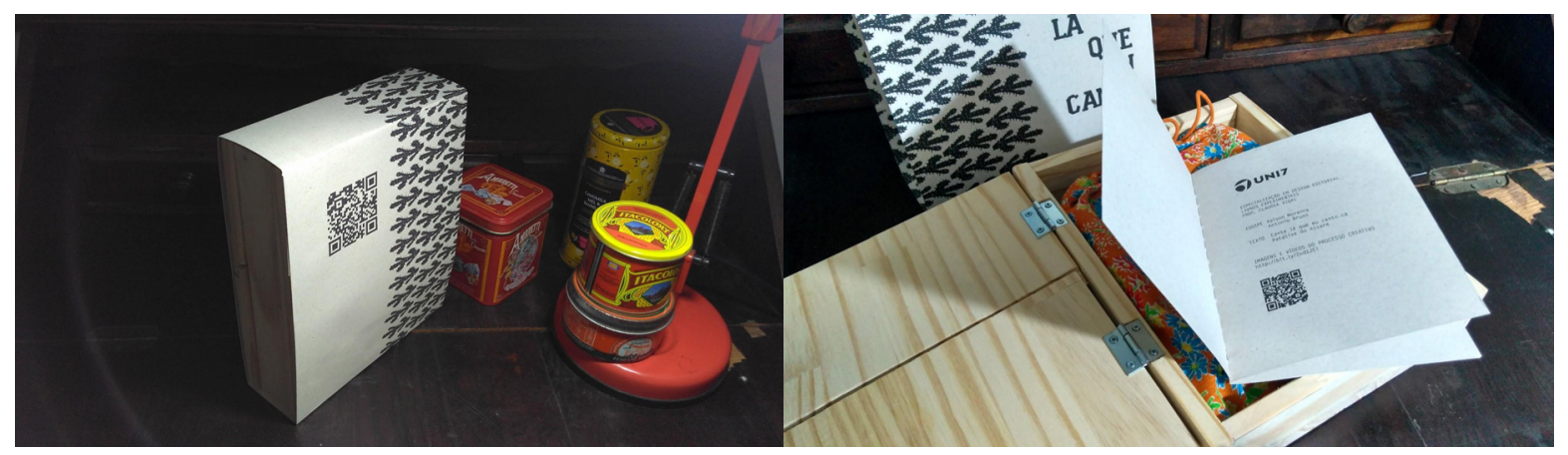

Imagem 4 - QRCODE impresso no verso da embalagem (à esquerda) e também no encarte que acompanha o livro (à direita) (Fonte: arquivo do autor. 2018) 


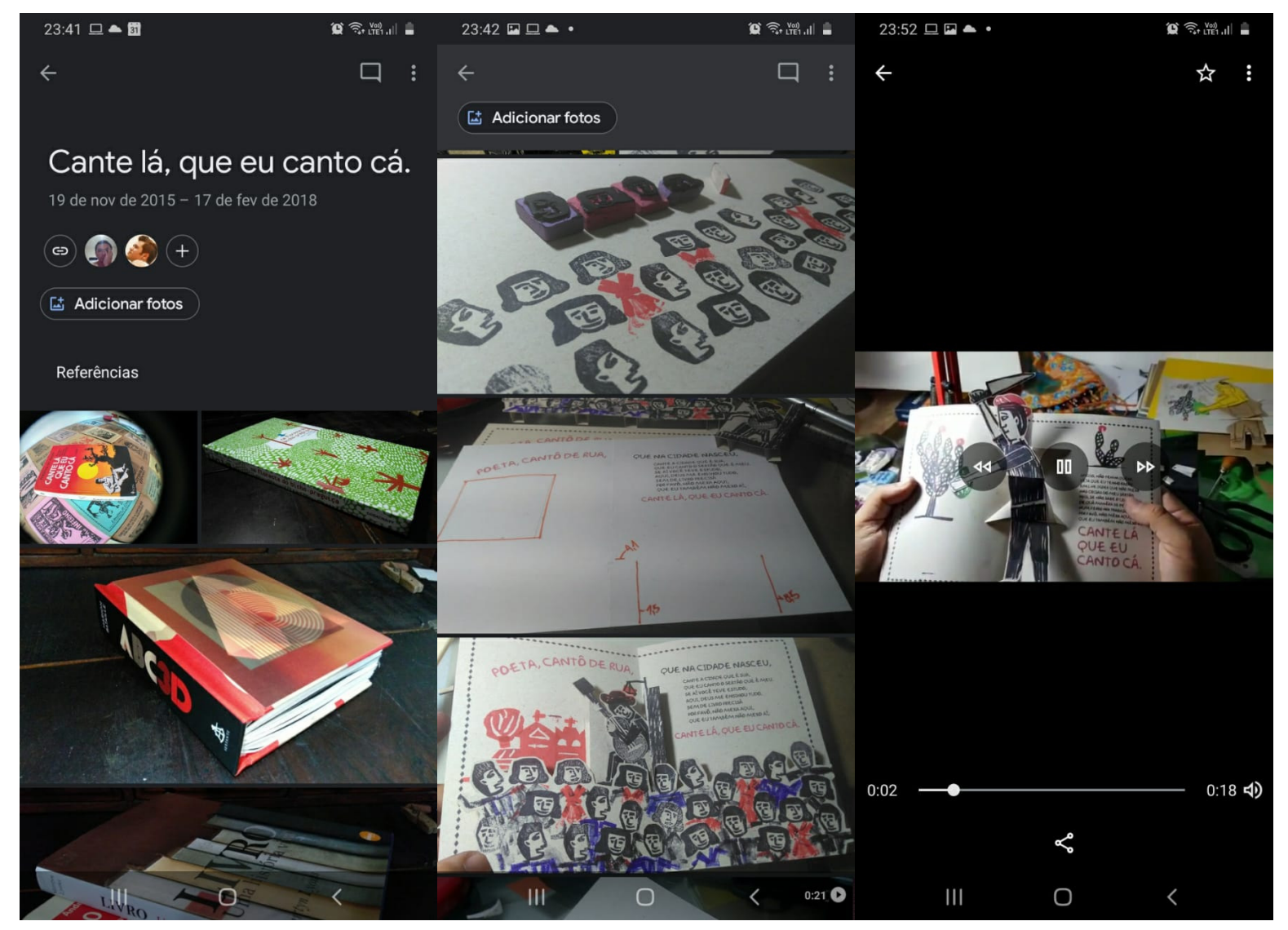

Imagem 5 - Prints de telas do Google Photos pelo smartphone, com o álbum do processo criativo (Fonte: arquivo do autor. 2018)

\section{Crítica Genética}

A partir daí começamos a fazer leituras reflexivas sobre a Crítica Genética onde encontramos um aporte teórico que poderia nos ajudar a lançar um outro olhar sobre o processo criativo, onde a noção do produto entregue é relativizado em detrimento de seu processo de criação.

Os estudos genéticos surgiram na França no início dos anos 70, com Louis Hay e Almuth Grésillon e estavam relacionados aos manuscritos de literatura. Foram introduzidos no Brasil por Philippe Willemart em 1985 e Cecília Almeida Salles é hoje um dos nomes mais representativos desta área em nosso país. Segundo ela:

A Crítica Genética surgiu com o desejo de melhor compreender o processo de criação artística, a partir dos registros desse seu percurso deixados pelo artista. [...] A Crítica Genética pretende oferecer uma nova possibilidade de abordagem para as obras de arte: observar seus percursos de fabricação. É, assim, oferecida à obra uma perspectiva de processo. (SALLES, 2008, p. 20)

Esses registros de experimentação são tratados pela autora como documentos de processo e indicam possibilidades, ou seja, o que a obra poderia ter sido. São de naturezas diversas podendo ser "encontrados em rascunhos, estudos, croquis, plantas, esboços, roteiros, maquetes, copiões, projetos, ensaios, contatos, story-boards" (SALLES, 2008, p. 40). São rastros deixados ao longo do processo, alguns abandonados em nome de escolhas para finalização da obra, mas sempre são pistas que mantém uma relação com a obra como ela é entregue ao público.

Pensando nisso, verificamos a necessidade de aplicar a Crítica Genética em nosso livro-objeto "Cante lá, que eu canto cá". Em outras palavras, utilizar a metodologia dos estudos genéticos para uma análise 
do nosso percurso de criação, estabelecendo relações entre os documentos de processo e entre estes e o livro na forma como ele foi apresentado.

Quando a Crítica Genética surgiu nos anos de 1970 na França, era um contraponto a outras formas de abordar o texto literário, pois, diferente dessas outras abordagens, escolheu para si um novo objeto: os manuscritos. Assim, teóricos da Crítica Genética, passaram a observar não mais o Texto sacralizado entregue ao público como obra acabada, mas sim o movimento de escritura, cujo produto apresentado não é mais que uma fase de um contínuo processo de criação. O objetivo, portanto, era uma literatura em movimento. Quanto à sua metodologia: desvelar o corpo e o curso da escrita por meio dos manuscritos, para construir uma série de hipóteses sobre a escritura. Refazer o caminho da criação sob a ótica do crítico. A isto, Jean Bellemin-Noël chamou de prototexto. Ou seja:

Um prototexto é uma certa reconstrução dos antecedentes de um texto, estabelecida pelo crítico com o auxílio de um método específico, destinada a ser objeto de uma leitura em continuidade com o dado definitivo. (BELLEMIN-NOËL, 1993, p. 141)

No cerne desse trabalho de elaboração do prototexto surgiram questionamentos fundamentais sobre o ato de escrever. "Lembraremos três dessas questões cuja tendência atual o estudo dos manuscritos pode modificar: a noção de texto, a de escrita e a de autor" (GRÉSILLON, 2002, p. 161).

Ao estabelecer um interesse pelos manuscritos criou-se uma relação entre prototexto e texto, onde o estudo de um, acima de tudo, enriquece o conhecimento do outro. Ao mesmo tempo, valorizar o prototexto significa também dessacralizar o texto, tirá-lo do pedestal, uma vez que se tornaria um estado entre outros. Além disso, ainda questionando a fixidez que era atribuída ao texto, Grésillon aponta uma série de obras cuja forma dependia dos manuscritos disponíveis e de como a obra era editada. Obras em que é impossível perceber um texto único. Enfim, tudo isso torna a separação entre prototexto e texto uma zona nebulosa.

O texto moderno, e esta não é uma descoberta pequena, adquire cada vez mais os aspectos de uma escrita sem fim. Se um é uma série de possíveis, o outro, que vem apesar de tudo fechar a série, pode de fato ser esse paradoxal "possível necessário", que certamente não é uma definição operatória da noção de texto, mas que evidencia a urgência de rever certas noções básicas das atividades literárias. (GRÉSILLON, 2002, p. 163)

Mas se o propósito de tudo isso é compreender o processo de criação da obra literária e os objetos de estudo são os rastros deixados pelos escritores em seus manuscritos, a pesquisa poderia e deveria ir além da literatura, uma vez que o estudo desses prototextos revelaram uma materialidade diversa do texto literário, ou seja, passou-se a observar não só a palavra escrita, como também rasuras, correções, esquemas, pequenos mapas, rabiscos, anotações deixadas nos cantos das páginas.

Muitas das vezes são encontradas correspondências do artista com outras pessoas tratando de sua obra. Enfim, tudo isso pode ser devidamente levado em conta na compreensão do fazer artístico. Segundo Cecília Almeida Salles:

Com a dilatação das fronteiras desses estudos, amplia-se o significado de manuscrito. Lida-se, assim, com índices de materialidades diversas: rascunhos, roteiros, esboços, plantas, maquetes, copiões, ensaios, story-boards e cadernos de artistas. (SALLES, 1998, p. 15) 
Isso significa que se o ato criador não se materializa somente na palavra escrita, então podemos também passar da literatura para outras manifestações diversas de arte, como cinema, arquitetura, artes plásticas, teatro, dança, etc. Fica aberto, portanto, o debate. Ou seja, "sob esse prisma, as discussões sobre os percursos de construção de obras não estão restritas ao campo da arte, abarcando outros processos comunicativos" (SALLES, 2006, p. 7). Sendo assim, Cecília opta por denominar essa gama diversa de rastros deixados durante o processo de criação, não mais de manuscrito - para fugir do âmbito apenas da literatura -, mas de documentos de processo. Trata-se não de uma mudança do objeto de pesquisa, mas de ampliar o seu alcance.

Ainda sobre a atuação de Cecília na pesquisa em Crítica Genética, e sua ampliação do conceito de manuscrito para documentos de processo, sabemos de seu trabalho desenvolvido sobre o processo criativo do escritor brasileiro Ignácio de Loyola Brandão, sobre o qual ela relata:

Mal sabia eu que iria entrar na complexidade e fascínio do labirinto que guarda alguns dos segredos de como ideias são geradas, são desenvolvidas, são escolhidas, são rejeitadas, são retomadas e são transformadas. (SALLES, 1996, p. 47)

Depois, aprofundando seus estudos com base em outras linguagens, manteve contato com artistas plásticos, dentre eles: Regina Silveira, João Carlos Goldberg e Evandro Carlos Jardim. Orientou também trabalhos de pesquisa em Crítica Genética sobre dança. Cita também o exemplo de um pesquisador com proposta de estudar um outro artista plástico que considerava seu mestre, sobre o qual ela diz:

O que está sendo analisado são alguns livros do artista - cadernos de anotações repleto de fotos de jornal e de revistas, anúncios, desenhos do artista, de seus alunos e de seus filhos, charges, entre muitos outros materiais. O pesquisador está estabelecendo relações entre esses cadernos e as obras do artista. (SALLES, 1996, p. 57)

Achamos ainda importante mencionar o estudo da própria Cecília sobre o processo de criação da Companhia 2, do Balé da Cidade de São Paulo, no projeto Todos os 12, uma vez que atuou de forma participativa pois estava presente como convidada, com autorização para fazer intervenções durante os ensaios para a construção da apresentação de dança, cujo foco era justamente a "reflexão sobre o processo de criação" (SALLES, 2008, p.105) e a percepção do corpo e de seus limites por parte de cada integrante do grupo.

\section{Conclusão}

Se nos interessamos pela observação dos documentos do processo criativo que deixamos ao longo do caminho percorrido até a apresentação do nosso livro-objeto "Cante lá que eu canto cá" é porque sabemos, retomando as palavras de Almuth Grésillon, que "o estudo de um virá a enriquecer o conhecimento do outro" (GRÉSILLON, 2002, p. 161). Nesse sentido, tal como aconteceu com os primeiros estudos em literatura, passamos a ver o produto final não como um objeto sacralizado, produto final acabado, mas apenas como um possível necessário que poderia ser diferente não fosse a urgência da entrega. Também nos sentimos muito à vontade para aplicar o método em um produto oriundo do Design, uma vez que já foi construída a abertura para áreas diversas da literatura, como mostram os exemplos de Cecília Almeida Salles apostados anteriormente.

Nos favorece aqui o fato de termos feito o registro fotográfico do nosso processo criativo. Sendo assim podemos reunir e classificar todo esse material, juntamente com outras anotações, desenhos, protótipos e outros elementos que tenham relação de significação com o produto na forma como ele foi entregue. A partir daí temos plenas condições de refazer a obra sobre o olhar do crítico, o que nos exige um constante trabalho de afastamento e aproximação, uma vez que nos encontramos no difícil papel duplo de autor, mas também de pesquisador.

Ainda no que diz respeito à conduta criadora, ressaltamos o importante papel do autor, uma vez que suas próprias referências culturais e históricas são evidenciadas em suas escolhas e aparecem nos 
documentos de criação. Citamos como exemplo um vídeo compartilhado no álbum de fotos mencionado, onde o autor dialoga com o próprio pai sobre as possibilidades que poderiam ser utilizadas na construção de uma das páginas do livro. Importante também lembrar que o processo criativo foi compartilhado em tempo real criando a possibilidade de uma rede com potencial para colaborar e interferir nas escolhas criativas do autor.

$\mathrm{O}$ produto que foi apresentado ao final da disciplina de livros experimentais, não só foi enriquecido pela sua extensão virtual, por meio do Google Photos, como o autor ganhou em capacidade argumentativa para defesa de seu projeto, uma vez que os registros possibilitaram a posterior retomada do processo criativo e uma anamnese constante da história de surgimento deste livro-objeto.

Cante lá que eu canto cá: the construction of the object book and the recording of the creative process using digital technologies

\section{Abstract:}

"Cante lá que eu canto cá" is an object-book created with techniques of graphic experimentation. His creative process was recorded in photos and videos and shared online, in real time, with the help of a smartphone and internet access. With the theoretical framework of Genetic Criticism, it was possible to resume the history of creating this product through the photos, videos, drafts and other documents generated during the creation process. This resumption not only enriches the discourse about the work created, but also shows a little of the author himself, his cultural and historical references.

\section{Keywords:}

Object book; Genetic Criticism; Creative process

\section{Referências bibliográficas}

BELLEMIN-NOËL, Jean. Reproduzir o manuscrito, apresentar os rascunhos, estabelecer um prototexto. Manuscrítica: Revista de Crítica Genética, São Paulo, p.127-161, dez. 1993. Semestral. Disponível em: http://www.revistas.fflch.usp.br/manuscritica/article/view/855/772. Acesso em: 13 ago. 2018.

BRASIL, Alexia. Cordel Digital. Fortaleza: Expressão Gráfica e Editora, 2005.

DUARTE, Jorge; BARROS, Antonio (Org.). Métodos e técnicas de pesquisa em comunicação. São Paulo: Atlas, 2005.

GRÉSILLON, Almuth. Devagar: obras. In: ZULAR, Roberto (Org.). Criação em processo: Ensaios de Crítica Genética. São Paulo: Iluminuras, 2002. p. 147-174.

GUZMAN, Cindy Triana. Aprendendo através de imagens: $O$ livro objeto. 2015. 99 f. Dissertação (Mestrado) - Curso de Artes Visuais, Escola de Comunicação e Artes, Universidade de São Paulo, São Paulo, 2015. Disponível em: http://www.teses.usp.br/teses/disponiveis/27/27160/tde-01122015101037/pt-br.php. Acesso em: 29 set. 2018.

HASLAM, Andrew. 0 livro e o designer II: Como criar e produzir livros. São Paulo: Edições Rosari, 2007.

LYONS, Martyn. Livro: uma história viva. São Paulo: Editora Senac São Paulo, 2011.

PASSERON, René. Da Estética à Poiética. In: Porto Arte: Revista de Artes Visuais, Porto Alegre: Instituto de Artes/UFRGS, v. 8, n.15, p. 103-116, nov. 1997. 
SALLES, Cecília Almeida. Arte e conhecimento. Manuscrítica: Revista de Crítica Genética, São Paulo, p.108-126, dez. 1993. Semestral. Disponível em:

http://www.revistas.fflch.usp.br/manuscritica/article/view/854/771. Acesso em: 07 ago. 2018.

SALLES, Cecília Almeida. Crítica Genética In Statu Nascendi. Manuscrítica: Revista de Crítica Genética, São Paulo, p.45-57, 1996. Semestral. Disponível em:

http://revistas.fflch.usp.br/manuscritica/article/viewFile/870/787. Acesso em: 18 ago. 2018.

SALLES, Cecília Almeida. Gesto Inacabado: processo de criação artística. São Paulo: FAPESP, 1998.

SALLES, Cecília Almeida. Redes da criação: construção da obra de arte. Vinhedo: Horizonte, 2006.

SALLES, Cecília Almeida. Crítica Genética: fundamentos dos estudos genéticos sobre o processo de criação artística. São Paulo: EDUC, 2008. 